\title{
DINÂMICA DO USO E COBERTURA DAS TERRAS NA BACIA HIDROGRÁFICA DO RIO ITAQUERI/SP, UTILIZANDO-SE MÉTODOS DE CLASSIFICAÇÃ̃O DIGITAL DE IMAGEM
}

\author{
Marcos Paulo Almeida Fornazieiro ${ }^{(a)}$, Andréia Medinilha Pancher ${ }^{(b)}$ \\ (a) Centro Universitário, Senac, marcosfornazieiro@yahoo.com.br \\ (b) Departamento de Planejamento Territorial e Geoprocessamento, Unesp - Rio Claro, medinilh@ @rc.unesp.br
}

Eixo: Uso e ocupação das terras e legislação ambiental

\begin{abstract}
Resumo
A multitemporalidade das imagens orbitais permite analisar o grau de transformação do uso e cobertura das terras ao longo dos anos e consequentemente as possíveis interferências antrópicas que afetam a funcionalidade e a qualidade ambiental dos territórios. Diante disso, este estudo teve como propósito analisar a dinâmica e a evolução do uso e cobertura das terras da bacia hidrográfica do rio Itaqueri SP, a partir da classificação supervisionada de imagens Landsat TM, adotando-se os classificadores Maxver - ICM e Bhattacharya, do SIG SPRING. Os resultados permitiram comparar a acurácia temática dos algoritmos e revelar, por fim, um panorama do uso e cobertura das terras da referida bacia nos cenários de 1989 e 2009, demonstrando o crescimento das áreas de solo exposto e área urbanizada em relação às áreas agrícolas, pastagem e campo sujo.
\end{abstract}

Palavras chave: Uso e cobertura das terras; Bacia hidrográfica; Classificação supervisionada; SIG.

\section{Introdução}

O acompanhamento das transformações espaciais do uso e cobertura das terras tem sido facilitado pelo avanço tecnológico das Geotecnologias, com destaque para as técnicas de processamento digital e classificação de imagens, maximizando os resultados para aplicabilidade no planejamento territorial e ambiental. Os principais desafios nos estudos de evolução dos padrões de uso e cobertura das terras, porém, concentram-se na dificuldade de acesso a um acervo histórico de imagens que preserve boa resolução espacial e espectral, permitindo-se, assim, um comparativo fiel e preciso entre as imagens multitemporais.

As imagens aerofotogramétricas constituem-se num excelente potencial para análises evolutivas dos territórios, devido à alta resolução espacial. Contudo, o custo para a obtenção desses produtos sensores é relativamente alto, pois, geralmente, para compor a área de estudo são necessárias várias imagens. Outro aspecto é que para a elaboração do mosaico de todas as imagens da área de análise, necessita-se de tempo considerável para o georreferenciamento de cada cena. Devido a esses fatores, a utilização de imagens orbitais de média resolução espacial, como às do satélite Landsat, constituem-se numa excelente 
alternativa, agilizando a elaboração do mapa temático de uso e cobertura das terras, à medida que uma cena abrange um extenso território (185 X 185km). Outra vantagem, é que essas imagens são produzidas em intervalos de tempo regulares, registrando as informações da mesma área a cada 16 dias. Também esses produtos sensores podem ser adquiridos gratuitamente do acervo do INPE.

Com base nas informações existentes nas imagens orbitais, é possível elaborar o mapa de uso e cobertura das terras, utilizando-se métodos de classificação supervisionada. Com base em Caetano, Santos e Gonçalves, (2002), esse mapa constitui-se numa ferramenta indispensável em estudos ambientais, na tomada de decisão em ordenamento e planejamento do território, e na definição de políticas públicas de gestão de recursos naturais. A partir do documento cartográfico, é possível medir a extensão e distribuição de classes de ocupação do solo, analisar a interação com outras classes, identificar locais próprios para determinadas atividades e planejar o futuro.

O conhecimento do uso das terras de uma determinada bacia hidrográfica é necessário para que se possa confrontar o uso atual com os diversos outros fatores que medem a real capacidade de uso de suas terras (DILL, 2002), enquanto que os impactos ocasionados pelas alterações do uso e manejo do solo na bacia refletem os processos de enchentes, vazões mínimas e médias, bem como as condições ambientais locais e a jusante (TUCCI; MENDES, 2006).

\section{Localização e caracterização da área de estudo}

Para o desenvolvimento deste trabalho, adotou-se como unidade de estudo a bacia hidrográfica do rio Itaqueri, a qual se limita ao sul com as bacias dos rios Jacaré Pepira e Passa-Cinco. O curso d'água principal dessa bacia é o rio Itaqueri, tendo como afluentes o ribeirão do Lobo, Córrego da Água Branca e Córrego do Geraldo, cujas águas alimentam a represa do Broa, também conhecida por represa do Lobo, situada próxima ao exutório da bacia. A bacia de estudo localiza-se entre coordenadas geográficas

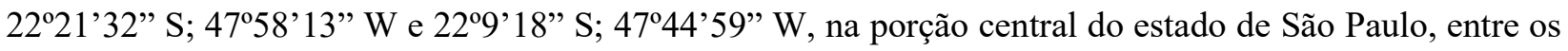
municípios de Itirapina e Brotas, conforme figura 1.

A região foi palco de profundas alterações paisagísticas desde a criação da Estação Experimental de Itirapina e posteriormente da Estação Ecológica de Itirapina. Verificou-se uma tendência à expansão das culturas agrícolas e da silvicultura em detrimento da cobertura vegetal nativa, como o cerrado, a mata, o campo sujo e as áreas de várzea. O pinus e o eucalipto avançaram sobre o cerrado e já começam a alcançar as margens da represa do Broa e as matas até então preservadas nos front das cuestas e morros testemunhos, assoreando afluentes a montante da represa. As culturas agrícolas, por outro lado, 


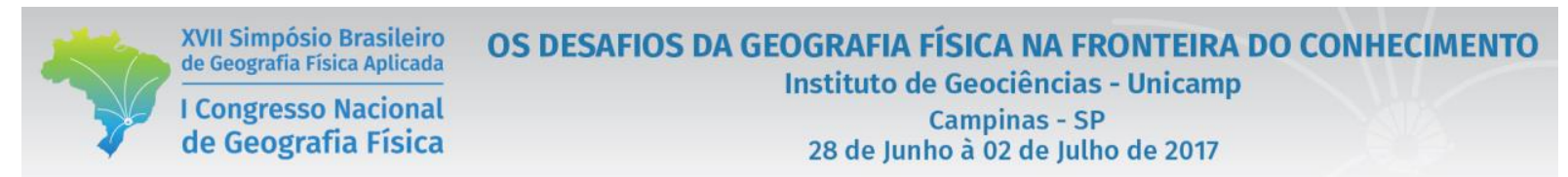

concentram-se ao redor da cidade de Itirapina e as pastagens localizam-se principalmente no centro-sul da área (MACHADO, 1997).
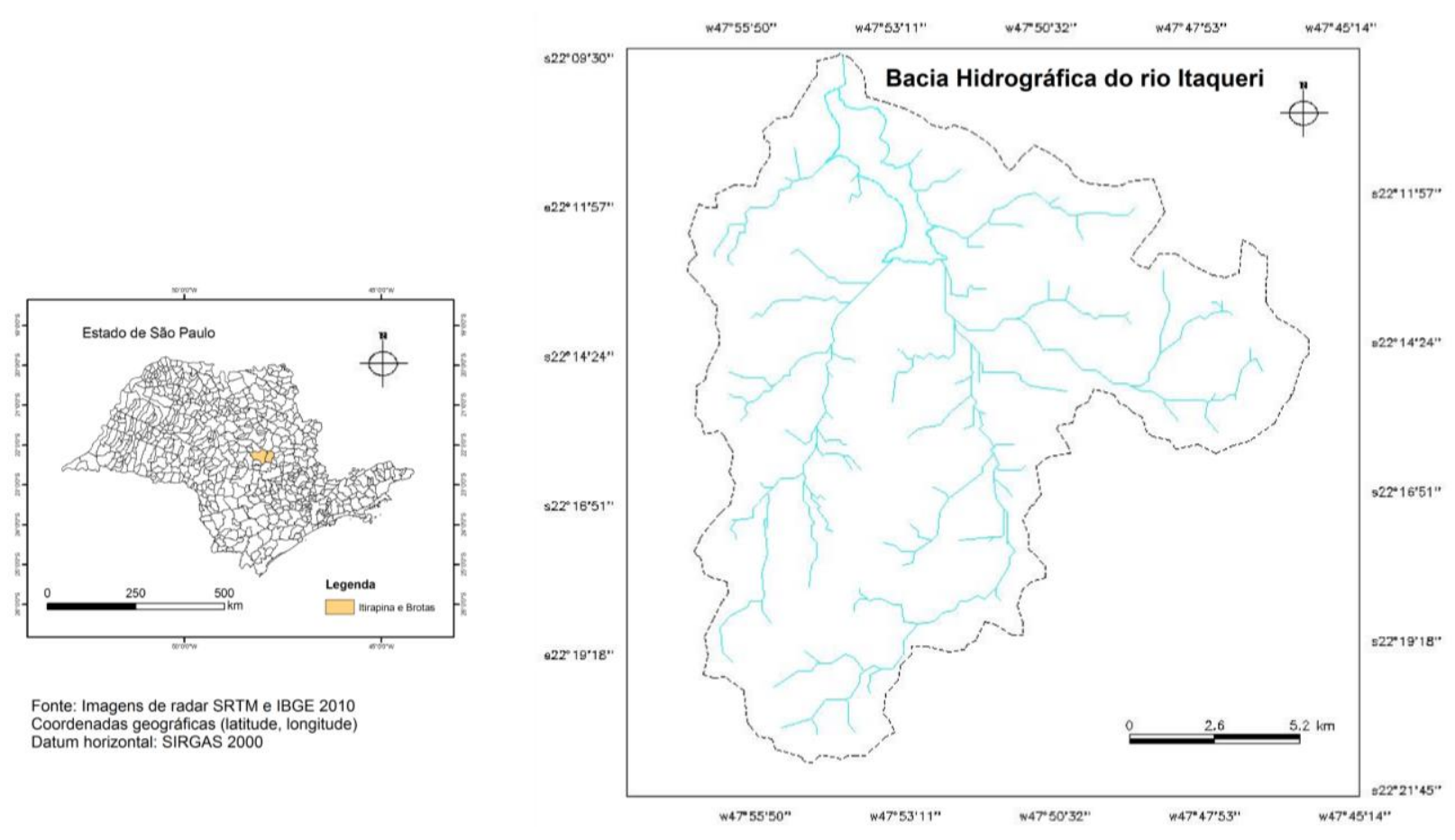

Figura 1 - Localização da bacia hidrográfica do rio Itaqueri/SP.

\section{Material e Métodos}

O material utilizado para o desenvolvimento deste trabalho foi adquirido junto ao catálogo de imagens orbitais do INPE, disponível gratuitamente no endereço eletrônico do instituto. Foram coletadas duas imagens do satélite Landsat TM 5 datadas de 17/05/1989 e 12/08/2009, ambas com 30 metros de resolução espacial nas 6 bandas espectrais do sensor Thematic Mapper (TM) e 120 metros na banda termal (6). Esse satélite tem capacidade de imagear uma área de $185 \mathrm{~km}$ a cada 16 dias, adotando uma resolução radiométrica de 8 bits.

As imagens foram georreferenciadas com base no mosaico de folhas topográficas do IGC (Instituto Geográfico e Cartográfico), adotando-se o Sistema de Projeção Universal Tranversa de Mercator (UTM) e datum planimétrico SIRGAS 2000, Fuso 23S. O erro quadrático médio dos pontos de controle do gerreferenciamento foi de 0,296 metro, atendendo, desta forma, ao PEC A para a escala 1: 10 000, conforme decreto $\mathrm{n}^{\circ} 89.817 / 1984$. Esse procedimento foi aplicado em ambas às imagens, permitindo-se o ajuste entre as cenas, de forma a tornar a análise multitemporal mais precisa. 


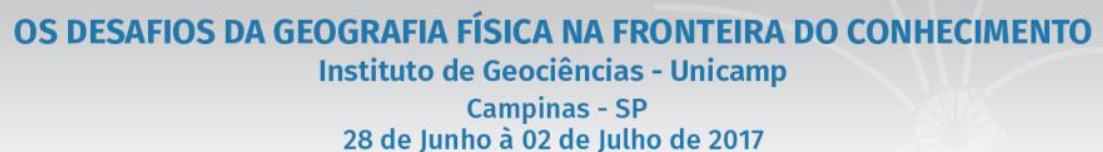

28 de Junho à 02 de Julho de 2017

$\mathrm{Na}$ sequência, foram aplicadas técnicas de processamento digital das imagens, no software de $S I G$ SPRING, com o intuito de melhorar a aparência das mesmas, ressaltar informações e facilitar o trabalho de classificação. A restauração permitiu restabelecer a qualidade original, bem como a resolução espacial das imagens que pode ter sido comprometida pelo tempo. O contraste, por sua vez, reequilibrou os níveis de cinza das imagens, os quais tendem a permanecer concentrados em um dado intervalo do espectro. Assim, os histogramas de todas das bandas multiespectrais RGB foram manipulados pela operação linear do SPRING.

Em seguida, adotou-se o filtro linear realce de imagem TM, sendo um recurso de filtragem do tipo passa alta. Desta forma, as feições de baixa frequência presentes nas imagens foram eliminadas, ao passo que as de alta frequência foram realçadas, permitindo-se ressaltar as bordas e os limites entre áreas de diferentes valores de nível de cinza, o que facilita a identificação dos limites entre os diferentes usos da terra.

Após a realização desses procedimentos de pré-processamento e de processamento digital das imagens, iniciou-se a etapa de classificação digital, a qual busca, a partir das características dos alvos, classificar automaticamente todos os pixels que compõem as imagens de maneira a associá-los a uma classe pertinente ao objeto real. Essa técnica é utilizada para estabelecer uma associação entre pixels com respostas espectrais similares, a qual pode ser aplicada no mapeamento de uso e cobertura das terras, tipos de vegetação, rochas e qualquer outra finalidade que vise o estabelecimento de classes (CRÓSTA, 1992 e IBGE, 2001).

Optou-se pela classificação do tipo supervisionada, na qual o analista possui participação direta por meio da coleta de amostras de pixels correspondentes a cada classe temática criada. Segundo Moreira (2011), a classificação supervisionada se resume em duas fases: treinamento e classificação. Na primeira, delimitam-se pixels representativos de cada classe de uso e cobertura das terras. Na segunda fase, o computador efetua a classificação tomando por base as amostras fornecidas pelo usuário.

A fim de estabelecer uma comparação, foram adotados os classificadores Maxver - ICM (Máxima Verossimilhança) e o Bhattacharya, do SPRING. O primeiro algoritmo aplica o método pixel a pixel para analisar as informações espectrais dos pixels de maneira isolada e também com relação à classe a que foi atribuída seus pixels vizinhos. O segundo algoritmo, por outro lado, demanda uma etapa preparatória, denominada segmentação, a qual agrupa os pixels de regiões espectrais semelhantes. Desse modo, o usuário atribui ao sistema amostras de polígonos para que o algoritmo possa identifica-los e rotulá-los em classes cujos níveis de cinza sejam similares.

Para o Maxver - ICM coletaram-se conjuntos de pixels representativos de cada classe temática preestabelecida, tomando-se o cuidado de adquirir várias amostras, considerando-se toda a variabilidade 


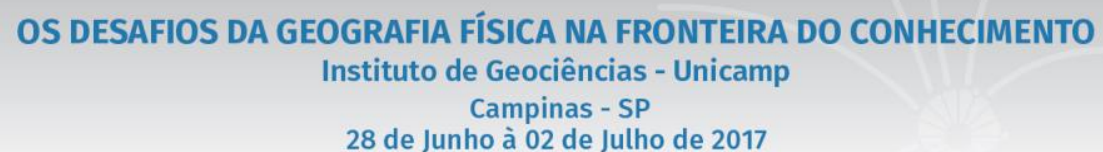

28 de Junho à 02 de Julho de 2017

de níveis de cinza de cada classe. Vale mencionar que o reconhecimento das classes se deu a partir da observação de elementos chaves para a fotointerpretação, tais como tamanho, forma, tonalidade e textura.

Para o Bhattacharya coletaram-se amostras a partir da imagem previamente segmentada. No processo de segmentação considera-se o limiar de similaridade e o tamanho de área. O limiar de similaridade busca definir a diferença mínima entre o valor de um pixel e a média do valor dos pixels que compõem a região para verificar se aquele pertence a esta região. Já o tamanho da área determina o menor valor de área em número de pixels que deve ser considerado na separação entre duas regiões (SPRING, 2011).

A fim de se obter um limiar de referência foi realizado um breve reconhecimento das imagens orbitais, adquirindo amostras espectrais dos pixels que compõem as futuras classes temáticas, conforme tabela I. Posteriormente, foi calculado o desvio padrão entre os valores dos pixels correspondentes a cada banda (Blue, Green, Red), os quais permitiram aferir acerca da dispersão estatística em relação à média.

Tabela I - Desvio Padrão para os valores espectrais das bandas RGB para as classes temáticas

\begin{tabular}{|c|c|c|c|c|c|c|c|c|c|c|c|c|c|c|c|c|c|c|c|c|c|}
\hline & \multicolumn{3}{|c|}{ Áreas Agrícolas } & \multicolumn{3}{|c|}{ Campo sujo } & \multicolumn{3}{|c|}{ Silvicultura } & \multicolumn{3}{|c|}{ Área Florestal } & \multicolumn{3}{|c|}{ Solo exposto } & \multicolumn{3}{|c|}{ Área urbanizada } & \multicolumn{3}{|c|}{ Água } \\
\hline \multirow{4}{*}{ 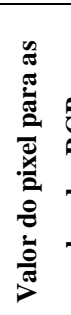 } & B & $\mathrm{G}$ & $\mathrm{R}$ & B & $\mathrm{G}$ & $\mathrm{R}$ & B & G & $\mathrm{R}$ & B & $\mathrm{G}$ & $\mathrm{R}$ & B & $\mathrm{G}$ & $\mathrm{R}$ & B & G & $\mathrm{R}$ & B & $\mathrm{G}$ & B \\
\hline & 57 & 142 & 97 & 77 & 111 & 118 & 20 & 106 & 41 & 51 & 109 & 40 & 159 & 131 & 199 & 170 & 166 & 245 & 52 & 33 & 5 \\
\hline & 54 & 142 & 97 & 67 & 110 & 139 & 13 & 111 & 0 & 47 & 116 & 27 & 153 & 149 & 197 & 130 & 152 & 254 & 55 & 19 & 3 \\
\hline & 52 & 171 & 67 & 79 & 105 & 118 & 21 & 150 & 19 & 45 & 102 & 34 & 156 & 134 & 192 & 165 & 144 & 233 & 24 & 13 & 3 \\
\hline 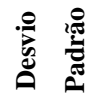 & 2,5 & 16,7 & 17,3 & 2 & 3,8 & 7,5 & 4,4 & 24,1 & 20,5 & 3,1 & 7,0 & 6,5 & 3 & 9,6 & 3,6 & 21,8 & 11,1 & 10,5 & 17,1 & 10,3 & 1,2 \\
\hline
\end{tabular}

A partir dos índices de dispersão espectral foram realizados alguns testes no algoritmo buscando-se determinar o melhor limiar de similaridade de acordo com o comportamento dos principais alvos presentes na área de estudo. Assim, com base nos resultados do desvio padrão da tabela I, definiu-se como índice inicial o limiar 4, afim de representar os menores índices de dispersão e verificar se a segmentação seria apropriada para a área de estudo como um todo. Em seguida, foram testados os índices 8, 16 e 24.

O objetivo dos testes foi definir valores não muito maiores ou menores do que aqueles alcançados pelos cálculos de desvio padrão, já que, segundo Oliveira (2002), os valores de limiares muito baixos podem apresentar uma fragmentação excessiva dos polígonos, tornando as regiões visualmente confusas. Por outro lado, os valores altos de limiares agregam segmentos de regiões espectralmente muito distintas, podendo ocorrer perda de informação. 
Com relação ao tamanho da área, Oliveira (2002) revela que o valor deve ser estabelecido levando-se em conta a escala de trabalho. Nesse caso, considerou-se a escala de 1:100.000 do sensor TM para definir os valores de limiar de área, o qual variou entre 100 e 200. Assim, foram cruzados os valores estabelecidos para o limiar de similaridade e área conforme a figura 2.

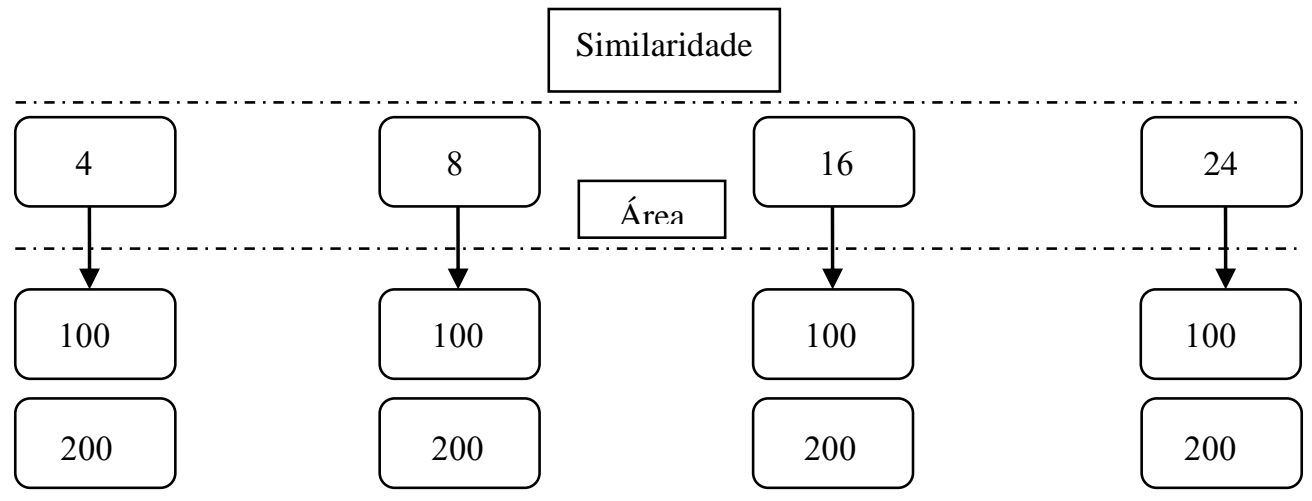

Figura 2 - Combinações dos pares de limiares de similaridade e área testados para a segmentação da imagem.

Após os testes, optou-se pelo limiar de similaridade 8 e área 100 (figura 3), os quais demonstraram-se satisfatórios, permitindo-se identificar áreas pequenas com usos significativos para o estudo, como pequenos núcleos urbanos, lagos menores e vegetações de várzea, o que não foi possível com a adoção de limiares maiores, uma vez que a variação espectral de pequenas áreas acabaram sendo generalizadas e agrupadas em regiões maiores e predominantes.

Depois da etapa de amostragem de pixels e regiões, foi realizada a classificação digital das imagens, sendo que os algoritmos Maxver - ICM e Bhattacharya do SPRING foram empregados nas análises com limiar de aceitação de $99 \%$. Os resultados foram comparados de acordo com o desempenho médio, confusão média e abstenção média, fornecidos pelo software, além da análise de acurácia e coerência das classificações resultantes. 


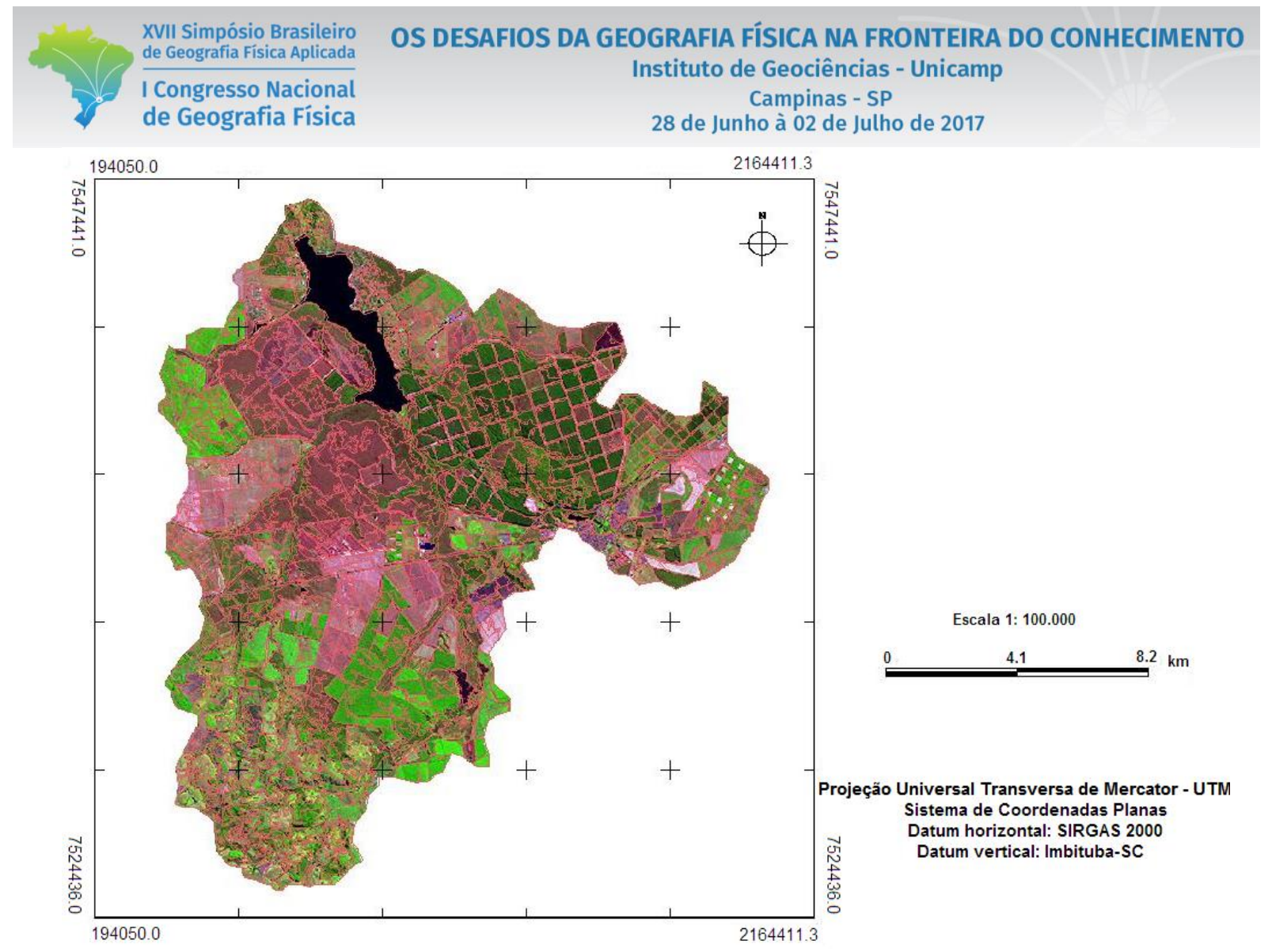

Figura 3 - Imagem segmentada com limiar de similaridade 8 e limiar de área 10.

\section{Resultados e Discussão}

Para a realização desse estudo, foram empregados os métodos de classificação supervisionada por regiões e pixel a pixel, representadas pelos algoritmos Bhattacharya e Maxver - ICM, respectivamente. O intuito foi identificar o método de classificação e o classificador mais adequado, avaliando-se, a acurácia e os indicadores de desempenho e confusão. O processo de classificação resultou no mapeamento de 8 classes temáticas: área urbanizada, pastagem, vegetação de várzea, campo sujo, área agrícola, solo exposto, silvicultura e área florestal.

Com base nos resultados obtidos constatou-se que a classificação por regiões mostrou-se mais adequada para o mapeamento temático pretendido (uso e cobertura das terras). A segmentação da imagem permitiu estabelecer zonas mais homogêneas, com respostas espectrais similares, uma vez que leva em conta o valor médio dos níveis de cinza de cada região e a matriz de covariância. Desse modo, o algoritmo Bhattacharya apresentou menor confusão média $(0,65 \%)$ entre as amostras coletadas para as classes de uso e cobertura das terras preestabelecidas, sem contar que obteve melhor desempenho (99,35\%). O algoritmo Maxver - ICM apresentou um desempenho inferior (88,54\%) e consequentemente obteve uma confusão média maior $(11,46 \%)$ entre as amostras. 
Ademais, com base na matriz de erro de confusão das amostras e o reconhecimento em campo das classes mapeadas, foi possível constatar que o classificador Maxver - ICM apresentou altos índices de confusão entre as classes área urbanizada e solo exposto devido à similaridade da resposta espectral destas classes, superestimando as áreas urbanizadas presentes na bacia estudada; também superestimou a classe vegetação de várzea em razão da confusão desta com as classes campo sujo e pastagem. Em contrapartida, o classificador Bhattacharya demonstrou maior precisão na delimitação dessas classes.

Em relação à qualidade visual, considerando-se que o Maxver - ICM classifica pixel por pixel, o mapa temático gerado apresentou um aspecto mais salpicado (também conhecido como efeito "sal pimenta"), com delimitação imprecisa das classes, dificultando o estabelecimento de padrões, comprometendo as análises e, consequentemente, limitando a aplicação do mapa (Figura 4). Por outro lado, o algoritmo Bhattacharya permitiu elaborar um mapa temático (Figura 5 e 6) mais preciso, com contornos das classes melhor definidos, facilitando as análises espaciais, tornando-se, assim mais adequado para o mapeamento de uso e cobertura das terras.
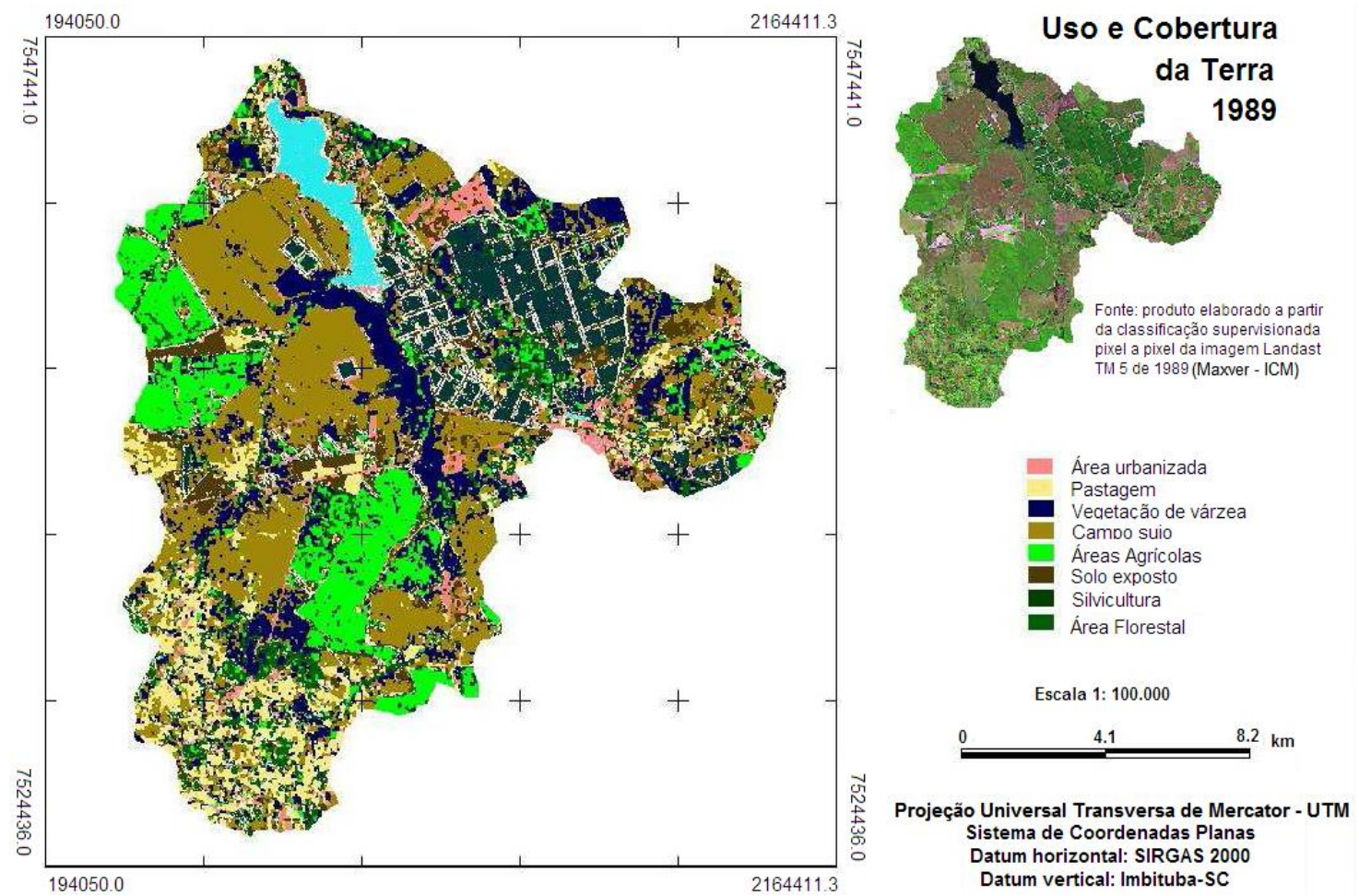

Figura 4 - Mapa de uso e cobertura da terra (1989) - classificação supervisionada pixel a pixel (Maxver - ICM). 

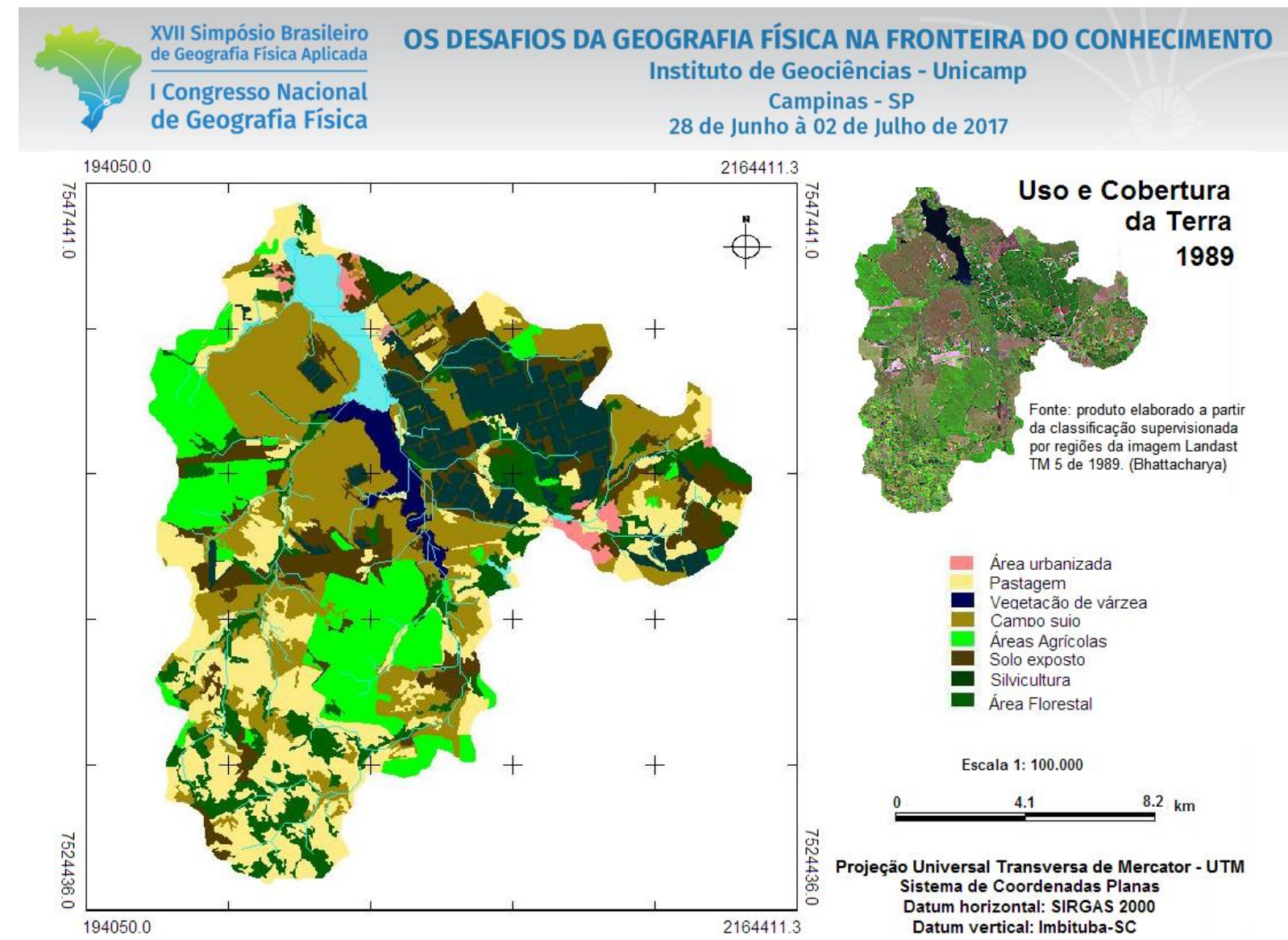

Figura 5 - Mapa de uso e cobertura da terra (1989) - classificação supervisionada por regiões (Bhattacharya).
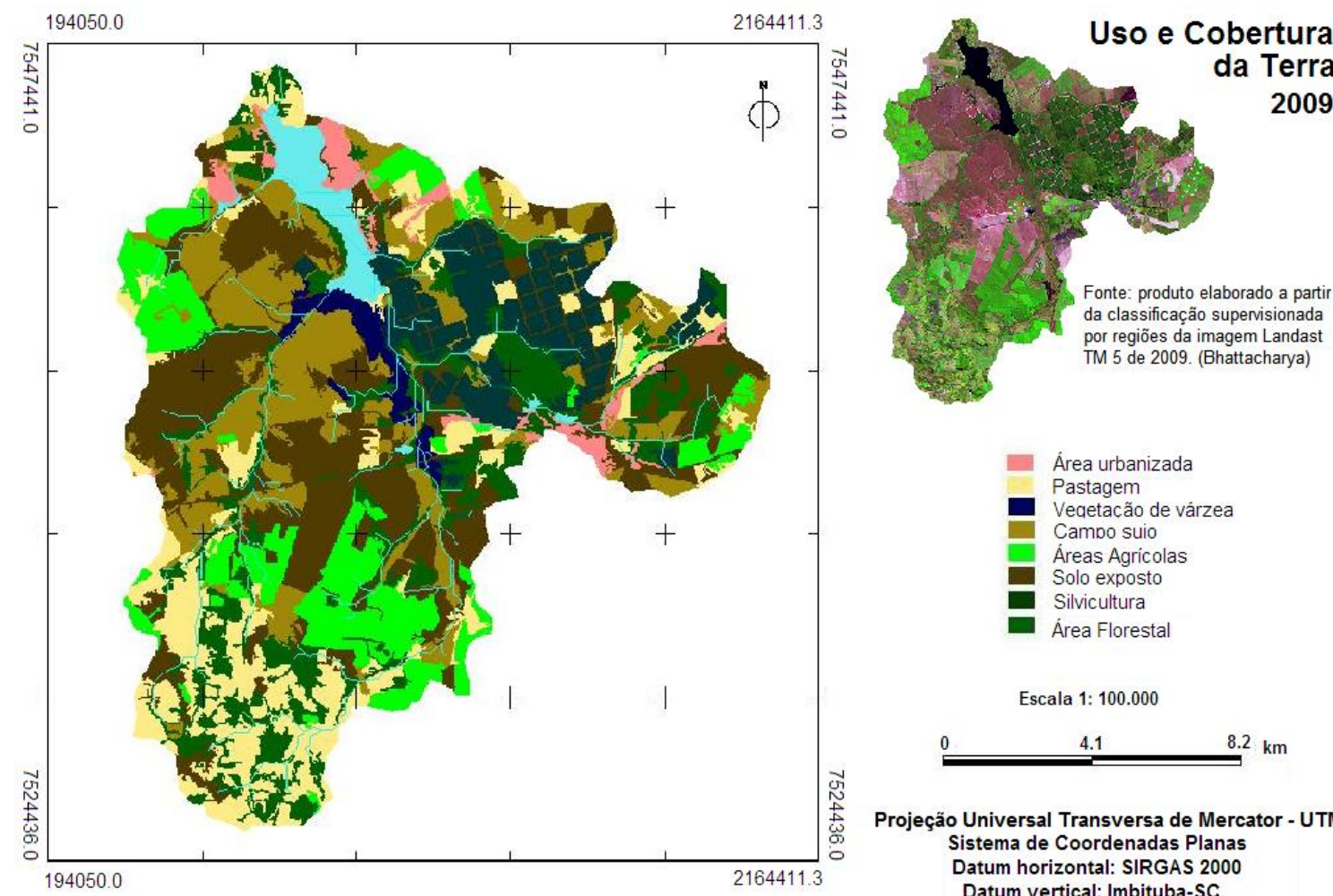

Figura 6 - Mapa de Uso e cobertura da terra (2009) - classificação supervisionada por regiões (Bhattacharya). 
XVII Simpósio Brasileiro

de Geografia Física Aplicada

I Congresso Nacional

de Geografia Física

\section{OS DESAFIOS DA GEOGRAFIA FÍSICA NA FRONTEIRA DO CONHECIMENTO \\ Instituto de Geociências - Unicamp \\ Campinas - SP \\ 28 de Junho à 02 de Julho de 2017}

Com base nos mapas de uso e cobertura das terras de 1989 e 2009 (Figuras 5 e 6), pôde-se mensurar a evolução dos tipos de uso e coberturas da bacia hidrográfica do rio Itaqueri SP.
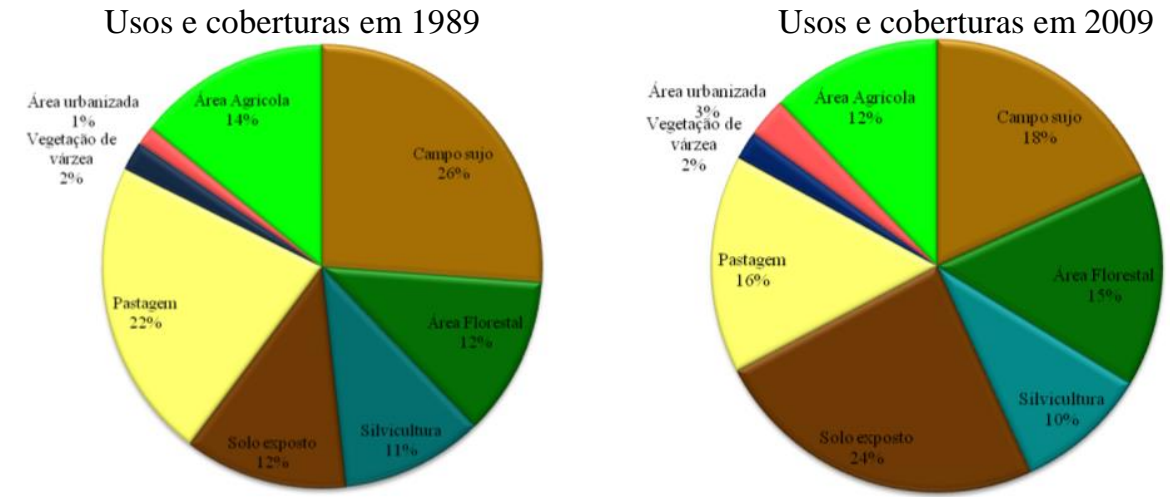

Figura 7 - Proporções (em \%) de Usos e Coberturas das Terras na bacia do rio Itaqueri - 1989 e 2009.

Como pode ser observado na figura 7, entre os anos de 1989 e 2009 constatou-se um aumento significativo nas áreas de solo exposto na bacia, aumentando de $12 \%$ para $24 \%$. O crescimento dessas áreas pode ser explicado em parte pela rotação de cultivos, visto que a bacia apresenta grandes zonas de uso agrícola sazonais como a cana de açúcar, em que os períodos de pós-colheita são caracterizados pelo manejo, correção ou pousio do solo.

A área urbanizada da bacia hidrográfica do Itaqueri sofreu um pequeno aumento, de 1\% (1989) para 3\% (2009), evidenciando o crescimento urbano de Itirapina nas últimas duas décadas. Segundo dados do IBGE (1991 e 2010), a população urbana do município passou de 8.686 habitantes em 1990 para 14.001 habitantes em 2009. Há que se destacar também a expansão urbana ao entorno da represa do Broa, sobretudo em razão do crescimento do turismo e lazer na região. O reservatório apresenta intensa atividade turística. De acordo com Tundisi; Matsumura Tundisi e Rodrigues (2003) a represa chega a receber 10 mil pessoas nos finais de semana e 30 mil visitantes nos feriados prolongados.

O Balneário Santo Antônio, situado na porção sudeste da represa, é o que apresentou crescimento urbano mais significativo no período considerado. Verificou-se um aumento da densidade populacional, com intensa ocupação dos lotes e redução das áreas verdes. Vale mencionar ainda que o acréscimo populacional próximo aos recursos hídricos, ocasionado pelo crescimento urbano e pela ampliação do número de turistas que frequentam o local, tende a afetar a qualidade e a integridade das águas pelo lançamento de efluentes não tratados, disposição irregular de resíduos e ocupação das Áreas de Preservação Permanente (APP).

Com relação às áreas agrícolas, detectou-se a presença mais significativa de cana-de-açúcar. Entre 1989 e 2009 houve um decréscimo de cerca de $2 \%$ desse tipo de uso na bacia hidrográfica, sobretudo em razão do 
preparo do solo para novos plantios, após o período de colheita. Verificou-se que a maioria das áreas de cultivo estão situadas próximas aos tributários do ribeirão do Lobo e do rio Itaqueri, bem como ao longo dos afluentes diretos da represa do Broa.

Também ocorreu a diminuição das áreas destinadas às pastagens, passando de 22\% (1989) para 16\% (2009). Em ambos os cenários, as pastagens estavam concentradas predominantemente na porção sul da bacia, região de maior altitude e próxima às cabeceiras do rio Itaqueri e ribeirão do Lobo. Em alguns locais, estas áreas foram substituídas por áreas agrícolas e solo exposto.

A classe temática correspondente às florestas aumentou pouco, de 12 (1989) para 15\% (2009). No entanto, no procedimento de classificação da cena de 2009, o classificador Bhattacharya apresentou certo índice de confusão entre as classes área florestal e área agrícola, em função das respostas espectrais de ambas serem similares. Isso ocorreu excepcionalmente nas extremidades da área agrícola situada na porção sul da bacia, onde alguns fragmentos de cana com maior vigor vegetativo foram considerados como pertencentes à classe área florestal.

O crescimento da vegetação nativa na área de estudo foi pequeno, contudo, houve aumento da vegetação no extremo norte da bacia hidrográfica, região próxima a foz do ribeirão do Lobo. Ao longo dos canais fluviais a presença da vegetação se mostrou rarefeita e, em vários pontos, inexistente nos dois anos analisados, aspecto que compromete a qualidade e quantidade das águas da bacia hidrográfica, uma vez que as matas galerias são essenciais para estabilizar o solo, evitando erosão das margens e o assoreamento dos cursos d'água, assim como é responsável por manter a vazão mínima dos rios. Quanto à cobertura do solo por silvicultura e vegetação de várzea, percebe-se que praticamente não houve alteração entre os anos de 1989 e 2009, tanto no aspecto quantitativo, quanto na sua distribuição espacial.

\section{Considerações Finais}

Com base nos resultados alcançados, a classificação supervisionada por regiões apresentou melhor desempenho de acordo com o propósito da pesquisa, quando comparada à classificação pixel a pixel. O algoritmo Bhattacharya mostrou menor confusão entre as amostras coletadas e maior desempenho médio em relação ao Maxver - ICM. Assim, os mapas temáticos de uso e cobertura das terras, oriundos do processo de classificação Bhattacharya, demonstraram as alterações ocorridas entre os anos de 1989 e 2009 na bacia hidrográfica do rio Itaqueri SP. Houve aumento expressivo das áreas de solo exposto em detrimento das áreas de cerrado, representadas pelo campo sujo. 
Também, houve aumento das áreas urbanizadas no período analisado, sobretudo com o adensamento urbano nas proximidades da represa do Broa, área que deve ser monitorada com atenção pelo poder público, tendo em vista que a ocupação tem contribuído para redução das áreas verdes e para o surgimento de grandes problemas socioambientais, como geração de resíduos, lançamento de esgoto in natura e parcelamento irregular do solo.

Diante do exposto, espera-se que os resultados obtidos nesse estudo, os produtos cartográficos elaborados, assim como os métodos empregados, possam subsidiar ações de planejamento e gestão do uso das terras em bacias hidrográficas, possibilitando análises variadas sobre a tendência de evolução do uso e cobertura das terras e desta forma identificar incompatibilidades com a capacidade de uso das terras e degradações dos recursos ambientais.

\section{Bibliografia}

BRASIL. Decreto n. 89.817/1984 de 20 de Junho de 1984 - Reguladoras das normas técnicas de cartografia nacional. Diário Oficial da União, Brasília, DF: Congresso Nacional, 1984.

CAETANO, M.; SANTOS, T.; GONÇALVES, L. Cartografia de ocupação do solo com imagens de satélite: estado da arte. Disponível em: www.igeo.pt/serviços/CDI/biblioteca/publicaçõesIGP_files/esig_2002/papers. Acessado em: 10 mar., 2007.

CRÓSTA, A.P. Processamento digital de imagens de sensoriamento remoto. Campinas, SP IG/UNICAMP, 1992. $170 \mathrm{p}$.

DILL, P. R. J. Assoreamento do reservatório do Vacacaí-Mirim e sua relação com a deterioração da bacia hidrográfica contribuinte. 2002. Dissertação (Mestrado em Engenharia Civil) - Universidade Federal de Santa Maria, 2002. 125f.

IBGE. Introdução ao processamento digital de imagens. Primeira Divisão de Geociências do Nordeste, Rio de Janeiro: IBGE, 2001.

MACHADO, L. M. C. P. A Represa do Lobo na percepção do usuário: contribuição ao zoneamento ambiental da APA de Corumbataí. Rio Claro: Instituto de Geociências e Ciências Exatas, 1997. 62 p.

MOREIRA, M. A. Fundamentos de sensoriamento remoto e metodologias de aplicação. Viçosa, MG: Ed. UFV, 2011. 422p.

OLIVEIRA, J. C. Índice para avaliação de segmentação (IAVAS): uma aplicação em agricultura. 2002. 160 p. Dissertação (Mestrado em Sensoriamento Remoto). Instituto Nacional de Pesquisas Espaciais, São José dos Campos. 2002.

SPRING. Apostila Processamento Digital de Imagens. Rio Claro: UNESP, 2011.

TUCCI, C.E.M.; MENDES, C.A.B. Avaliação Ambiental Integrada de Bacias Hidrográficas. Ministério do Meio Ambiente e PNUD. Brasília-DF. 2006. 362p.

TUNDISI, J. G.; MATSUMURA TUNDISI, T.; RODRIGUES, S. L. Gerenciamento e recuperação das bacias hidrográficas dos rios Itaqueri e do Horto/Itaqueri e da UHE Carlos Botelho. Instituto Internacional de Ecologia, 2003. 72p. 